\title{
Prospects: An increasing focus on curriculum, learning, and assessment
}

\author{
P. T. M. Marope ${ }^{1}$
}

Published online: 17 July 2015

(C) UNESCO IBE 2015

I am pleased to introduce our first non-thematic collection of peer-reviewed articles in 2015. As we move toward making the International Bureau of Education (IBE) a global Center of Excellence, we continue to gradually shift the focus of Prospects, so it can more effectively address IBE's mandate and strategic goals. The heart of our work is strengthening the capacity of education systems to equitably provide high-quality education and effective learning opportunities - thus contributing to quality Education for All. Likewise, Prospects increasingly focuses on issues central to our broad efforts to produce, compile, and disseminate up-to-date information and analyses in the areas of curriculum, learning, and assessment.

In this issue we include articles that bear directly on these three areas, with topics ranging from curriculum reform and inclusive education to active learning, vocational training, and formal, nonformal, and informal learning. Specifically, the articles examine research-based early-grade reading programmes; teacher enactment of active-learning pedagogy; disability-inclusive indicators that are local and contextually applicable; instruction in local language as one aspect of the right to education; engagement of higher education institutions in disaster prevention and mitigation; access to different types of learning and training in rural areas; and the duality principle (the integration of theory and practice in the context of vocational education and training). Besides adding substantive arguments to ongoing scholarly debates, all the articles also develop valuable recommendations for policymakers.

John P. Comings proposes a research-based model for design of early-grade reading programmes. The model has three components: (1) schools should provide instruction in a language their students speak and understand; (2) teachers should employ instruction that is consistent with the current evidence-based theory of how children acquire and improve reading skills; and (3) to make meaningful progress, students should spend sufficient time

P. T. M. Marope

ibe.prospects@unesco.org

1 UNESCO International Bureau of Education, C.P. 199, 1211 Geneva 20, Switzerland 
on-task in direct instruction and reading practice. Comings describes how reading programmes are trying to implement each component, and gives the evidence that supports those approaches. He concludes by discussing ways this programme model could inform policy and be improved by further research.

Rhonda Di Biase reports the findings of the first phase of a design-based research study that investigates teacher enactment of active-learning pedagogy in the Maldivian education system. This initial phase involved the participation of school-community stakeholders in the World Café (a participatory data-collection approach), to identify their perceptions of and priorities for active learning. Using this innovative research approach that encourages collaborative dialogue, she seeks to develop a shared vision of active learning that would respond to local realities.

Chris Forlin, Umesh Sharma, Tim Loreman, and Beth Sprunt review the existing literature on inclusive education in the Pacific Islands as a first step in developing a set of local and contextually applicable indicators that can be applied across the region. They find clear evidence of growing interest in inclusive education; additionally, they notice that international conventions, declarations, and statements promoting inclusion have led to the development of policy at both regional and country levels within the Pacific-though various international approaches have disregarded local cultural issues and the region's changing social profile. The authors highlight themes highly pertinent to monitoring inclusive education in the Pacific Islands, as well as suggestions for building on and improving inclusive education for people with disabilities. While disability-inclusive indicators within the Pacific Islands are very limited at present, policymakers may use recognized strategies, good practices, government recommendations, and outcomes from across the region to shape their development.

Zehlia Babaci-Wilhite looks at recent developments in linguistic choices in education and examines the arguments for using local languages of instruction as a right. Her article analyzes the curriculum change in Zanzibar, where English replaced Kiswahili as the local language of instruction in the last two years of primary school in mathematics and science. She concludes that expanding the use of English in primary school would reduce the quality of teaching and learning, which would violate the educational rights of Zanzibari children. Babaci-Wilhite argues that relying on local language and local knowledge in education would contribute to children's well-being, which is underpinned in part by their right to education. It would help them become confident in their community and able to understand and engage with the world on their own terms.

Hoda Baytiyeh discusses the essential role that Lebanese institutions of higher education should play in educating the public about earthquake risk and in preparing the public to take risk-reduction measures. She argues that, although Lebanon faces the risk of powerful earthquakes with potentially devastating effects, the Lebanese people in general do not recognize this risk because educational programs and government officials have failed to inform them. The author calls for the integration of earthquake-risk education into academic programs and for the establishment of research facilities and student volunteer programs on university campuses across Lebanon. These initiatives, Baytiyeh argues, would reduce the impact of future earthquake disasters and make Lebanese communities more resilient to future crises. Unless higher education institutions engage in disaster prevention and mitigation, Lebanese communities will remain vulnerable to massively destructive earthquakes.

Matthias Pilz and Simon Wilmshöfer examine the access young people in rural India have to different types of learning and training-with a particular focus on vocational processes (skill formation) - and what challenges they face. They investigate the area 
around the Chilika Lagoon, a rural region in the eastern state of Orissa, by interviewing fishing families about formal and nonformal education and informal learning activities and by tracking their children's daily activities to determine educational levels, learning activities, and the demand for education and training.

Santosh Mehrotra, Kalaiyarasan A., Neha Kumra, and K. Ravi Raman engage with the duality principle - the integration of theory and practice in the context of vocational education and training - and empirically assess its usefulness and replicability in India, based on a primary survey of skill requirements of German and Indian firms in India. The authors make a strong case for adapting some of the critical elements of the German dual system to render Indian VET more responsive to the labour market and to provide a formally structured and integrated system of skill development.

The articles gathered in this issue of Prospects are indicative of our continuous efforts to publish high-quality research on emerging topics that attract the attention of educators and policymakers. We also hope that this issue will further influence education debates on curriculum, learning, and assessment-e.g., in rethinking curriculum structures and objectives, approaches to teaching and learning, and assessment systems within the framework of a holistic vision of education. 